\title{
Possible Health Implications and Low Vitamin D Status during Childhood and Adolescence: An Updated Mini Review
}

\author{
Dimitrios Papandreou, ${ }^{1}$ Pavlos Malindretos, ${ }^{2}$ Zacharoula Karabouta, ${ }^{1}$ and Israel Rousso ${ }^{1}$ \\ ${ }^{1}$ 2nd Department of Pediatrics, Aristotle University of Thessaloniki, School of Medicine, Ahepa General Hospital, \\ St. Kiriakidi 1, 54636 Thessaloniki, Greece \\ ${ }^{2}$ Department of Pathology, Aristotle University of Thessaloniki, School of Medicine, Ahepa General Hospital, \\ St. Kiriakidi 1, 54636 Thessaloniki, Greece \\ Correspondence should be addressed to Dimitrios Papandreou, papandreoudimitrios@yahoo.gr
}

Received 31 March 2009; Accepted 17 June 2009

Academic Editor: Suzanne E. Judd

Copyright ( $\odot 2010$ Dimitrios Papandreou et al. This is an open access article distributed under the Creative Commons Attribution License, which permits unrestricted use, distribution, and reproduction in any medium, provided the original work is properly cited.

\begin{abstract}
Vitamin D deficiency is common in the developing countries and exists in both childhood and adult life. The great importance of Vitamin D is the moderation of calcium $(\mathrm{Ca})$ and phosphorus $(\mathrm{P})$ homeostasis as well as the absorption of Ca. While insufficiency of vitamin D is a significant contributing factor to risk of rickets in childhood, it is possible that a more marginal deficiency of vitamin D during life span contribute to osteoporosis as well as potentially to the development and various other chronic diseases such as cardiovascular disease, cancer and diabetes. This paper reviews the metabolism, epidemiology, and treatment of vitamin $\mathrm{D}$ and calcium insufficiency as well as its relation to various diseases during childhood and adolescence.
\end{abstract}

\section{Introduction}

1.1. Vitamin D Metabolism. Vitamin D has two different forms: Vitamin D2 which exists in food (plants) and D3 (cholecalciferol) which is produced by following the path 7 -dehydrocholesterol $\rightarrow$ previtamin D $\rightarrow$ vitamin D3 in the skin upon ultraviolet B (UVB) sun exposure and at skin temperature. The process of generating vitamin D3 from sun exposure is attenuated by reduced exposure of the skin to sunlight (northern latitudes with decreased direct sun exposure, air pollution, confinement indoors, clothes covering all the skin, broad use of sunscreens, increased skin pigmentation) or in dermatologic conditions such as ichthiosis in which sun inadequately penetrates the epidermis [1]. The two vitamin D molecules differ in structure; vitamin D2 has an extra double bond between carbons 22 and 23 and an additional 24-methyl group in comparison with vitamin D3 having been demonstrated to be two to three times more effective than vitamin D2 [2-4]. Both forms of the vitamin $\mathrm{D}$ diffuses into the circulation and is transported protein-bound to the liver where it is hydroxylated to $25(\mathrm{OH}) \mathrm{D} 3$ (calcitriol) and $25(\mathrm{OH}) \mathrm{D} 2$. Serum or plasma $25(\mathrm{OH}) \mathrm{D} 3$ is the most commonly used and appropriate biochemical marker of vitamin D status $[5,6]$. In the kidney, $25(\mathrm{OH}) \mathrm{D} 3$ undergoes a further hydroxylation at the first carbon, catalysed by 1,2-hydroxylase, to form 1,25(OH)2D3 which is the biologically most active form of vitamin D [6]. Although 1,25(OH)2D3 represents the active form of the vitamin, due to a tight regulation of its production as well as a relatively short half-life (4-6 hours), it is not a good indicator of vitamin D status [5-7]. Serum 25(OH)D3 concentrations are the best indicator of determining adequacy because it represents the combined amounts of vitamin $\mathrm{D}$ synthesized in the skin and dietary sources [8]. Serum 25(OH)D3 levels are the accepted measure of vitamin D nutritional status [9].

1.2. Prevalence of Vitamin D Deficiency. In the USA, cases of nutritional rickets have been reported from at least 17 states, with 166 cases reported in the medical literature between 1986 and 2003 [10]. Relatively high rates of subclinical vitamin $\mathrm{D}$ deficiencies have been reported in otherwise healthy infants $[11-14]$ children $[15,16]$ and adolescents $[17$, 18] in several American states. A high prevalence of vitamin $\mathrm{D}$ deficiency has also been reported in infants, children, and adolescents from diverse countries around the world, 
including the UK [19], France [20], Greece [21], Lebanon [22], Turkey [23], China [24], Finland [25, 26], Canada [27, 28] and Qatar [29]. In the research that took place in China, $18 \%$ of total 42 healthy infants were found with rickets and the fact that not all infants with rickets in this study had low $25(\mathrm{OH}) \mathrm{D}$ concentrations suggests 2 possibilities: (1) not all rickets is necessarily related to a vitamin D deficiency, or (2) serum $25(\mathrm{OH}) \mathrm{D}$ concentrations are not the best indicator of vitamin D status [30]. Among adolescence, reported prevalence rates of vitamin $\mathrm{D}$ deficiency have ranged from 0 to $42 \%$, with variation noted secondary to season, latitude, and participant race/ethnicity [31]. Data from national surveys in the UK, USA and New Zealand show that the prevalence of low vitamin D status is less of a concern for children than for adolescents [32-34]. There is also some suggestion that intakes of vitamin D may be worse in females than males. For example, Moore et al. reported that adolescent males in the USA were the group most likely to consume the adequate intake value for vitamin $\mathrm{D}$, while adolescent females were about half as likely as males of corresponding age to meet their dietary reference intakes [35].

Vitamin D status changes were also reported using data from the National Health and Nutrition Examination Surveys (NHANES). The authors concluded that the mean serum 25(OH)D was lower in 2000-2004 than 1988-1994 and that the assay changes unrelated to changes in vitamin D status accounted for much of the difference in most population groups. They also reported that in the adult subgroup, combined changes in BMI, milk intake, and sun protection appeared to contribute to a real decline in vitamin D status [36]. In addition, Bener et al. [29] recently found a very high incidence of vitamin $\mathrm{D}$ deficiency in the young population in Qatar especially in girls. This deficiency attributed by the authors as a result from a combination of limitation in sunlight exposure and a low oral intake of vitamin D. Also, children with renal failure are at risk for vitamin D deficiency. Recently Ali et al. [37] studied over a period of 10-years the prevalence in children with vitamin D efficiency and he found rates from $20 \%$ to $75 \%$.

\section{Health Implications of Vitamin D Deficiency}

Increasing evidence suggests that optimal vitamin D status throughout the lifespan - even in utero-may be important not only in maintaining bone health, but also in protecting against many chronic conditions, including autoimmune diseases, diabetes, cardiovascular diseases, and cancer [38].

2.1. Rickets. Rickets was a very common disease during the industrialization and had a prevalence of $40 \%-60 \%$ in children living in northern Europe [39]. Rickets was cured after people were informed about the value of vitamin $\mathrm{D}$ in bone conformation and the adequate exposure to sunlight as a prohibitive and therapeutic method. Cod liver oil and fortification of infant formula also helped on this direction. The problem began to reappear in 1960, especially among breastfed infants and in those infants whose mothers' dress included covering [40]. Over the past 20-30-years, there has been a reemergence of rickets with reports in the UK [4143], Europe [44-46],North America [47] and Saudi Arabia [48] in a variety of ethnic groups. The resurgence of rickets in North America in the 1990s coincided with skin cancer prevention campaigns [49]. Studies in South Africa and Nigeria suggest that a dietary deficiency of calcium may cause rickets $[50,51]$ and there are case reports of rickets caused by dietary calcium deficiency in North America $[52,53]$. Most of the children in these studies had normal serum 25-hydroxyvitamin D concentrations and high serum 1,25dihydroxyvitamin $\mathrm{D}$ concentrations, indicating adequate intake of vitamin D. Other possible reasons for the increasing prevalence of rickets include: breastfeeding without vitamin D supplementation, vegetarian diets [54], darker-skinned people migrating to countries with less sunlight $[45,55,56]$ and increasing atmospheric pollution [57]. Typically, rickets associated primarily with vitamin D deficiency presents during the first year of life.

\subsection{Vitamin D Status and Type 1 Diabetes Mellitus (T1DM).} T1DM is among the most prevalent chronic diseases with onset in childhood, being the second most common chronic disease in children after asthma in the USA. It results from an immune-mediated destruction of pancreatic insulinproducing $\beta$-cells, with both genetic and environmental factors playing roles in the aetiology. It is linked about $60 \%$ to genes in the HLA complex of the major histocompatibility complex (MHC) on chromosome 6p21 [58, 59]. Non-MHC chromosomal regions are also involved, particularly the regulatory region of the insulin gene and the interleukin1 receptor type 1 gene. The specific factors that initiate the autoimmune process are not yet well understood, but $\beta$ cell destruction often begins during infancy and continues over many months or years [60]. By the time T1DM is diagnosed, about $80 \%$ of the b cells have been destroyed. There is a marked geographic variation in incidence, with a child in Finland being about 400 times more likely than a child in Venezuela to acquire the disease [60]. The pattern follows a latitudinal gradient that is the inverse of the global distribution of ultraviolet B (UVB) irradiance. It is estimated that currently the incidence is increasing by $3 \%$ per year. Furthermore, it is predicted that by 2010 the incidence of T1DM will be $40 \%$ higher than it was a decade earlier [60].

One of the environmental factors thought to be protective against the development of T1DM, is early supplementation with vitamin D. Vitamin D is either produced endogenously, through skin exposure to sunlight, or exogenously from ingestion of foods and supplements $[59,60]$. T1DM incidence rates are higher in regions that are more distant from the equator, where UVB irradiance is lower, than in those closer to the equator, where UVB irradiance is much higher. Although the importance of vitamin D for preventing rickets and adult bone disease is well established, it is becoming increasingly clear that vitamin D appears to be an immunosuppressive agent, a role that may explain its protective association with autoimmune conditions, including multiple sclerosis and rheumatoid arthritis. Strong evidence of a vitamin D effect on T1DM risk comes from experiments in the nonobese diabetic (NOD) mouse. The 
NOD mouse experiences disease pathogenesis similar to the human, including autoimmune destruction of $\beta$-cells. When 1,25-dihydroxyvitamin $\mathrm{D}(1,25(\mathrm{OH}) 2 \mathrm{D})$, the active form of the vitamin, was administered to NOD mice in pharmacologic doses, it prevented the development of diabetes. More recently, NOD mice raised in a vitamin D deficient state were shown to develop diabetes at an earlier age than nondeficient NOD controls [59-61]. The dependence of normal insulin secretion in pancreatic $\beta$-cells on vitamin $\mathrm{D}$ has been known for several decades. A reduction in vitamin $\mathrm{D}$ activity can result in both increased insulin resistance and reduced insulin secretion. Epidemiological data have shown a four-to five-fold higher prevalence of noninsulindependent diabetes in dark-skinned Asian immigrants in comparison with British Caucasians indicating that low vitamin $\mathrm{D}$ status may contribute to the pathogenesis of diabetes [62].

A recent review including studies from many European countries, particularly the EURODIAB [63], and the Finnish study [64] in 2001, concluded that there is evidence from observational studies that vitamin D supplementation in infancy might be protective against the development of T1DM. The EURODIAB study found that children whose mothers consumed vitamin D supplements during pregnancy had a lower risk of type 1 diabetes than those whose mothers did not, and indicated that children being supplemented had a $29 \%$ reduction in risk of developing type 1 diabetes compared with their peers who were not being supplemented. The favourable association with vitamin D persisted after adjustment for birthweight, duration of breast feeding, maternal age and study centre [61]. A Norwegian study done by Stene and jones [65] in 2003 looked at the effect of the time of starting supplementation with vitamin D. It appears that those who had cod liver oil, an important source of both vitamin $\mathrm{D}$ and the long-chain n-3 fatty acids docosahexaenoic acid (DHA)and eicosapentaenoic acid (EPA) in the Norwegian population between 7 and 12 months of age had lower chances of developing T1DM in later life compared to those who were supplemented between 0 and 6 months of age. More recently, significant vitamin D deficiency was found in more than $75 \%$ of 128 children with type 1 diabetes [66]. Epidemiological studies describing a north south gradient in incidence rate and an inverse correlation between incidence and mean monthly sunshine hours are also hinting at a possible protective effect of vitamin $\mathrm{D}[62,63]$. In conclusion, the evidence shows that the vitamin $\mathrm{D}$ system plays an important role in T1DM. By interfering with environmental factors, such as sun exposure and subsequent vitamin $\mathrm{D}$ levels, there may be an opportunity to prevent some of the cases of T1DM. So, the provision of adequate levels of vitamin D is an important goal for public health [61]. Considering the rapid increase in type 1 diabetes incidence among $0-$ 5 -year olds and early appearance of IA, maternal intake of certain dietary nutrients during pregnancy including vitamin $\mathrm{D}$ through food, may provide sufficient in utero exposure to these nutrients, offering early protection from or promotion of islet autoimmunity (IA) in infancy or early childhood $[63,67,68]$.
2.3. Vitamin D Status and Other Diseases. While rickets and osteomalacia are the index diseases for severe vitamin D deficiency, there has been growing evidence that less severe deficiency, may also contribute to other chronic diseases, such as cardiovascular disease, hypertension, cancer and other chronic disease.

The active form of vitamin D, 1,25-dihydroxyvitamin D, is made in many different tissues, including colon, prostate, and breast. It is believed that the local production of $1,25(\mathrm{OH}) 2 \mathrm{D}$ may be responsible for the anticancer benefit of vitamin D. In a recent review by Holick [69] suggested that women who are vitamin D deficient have a $253 \%$ increased risk for developing colorectal cancer, and women who ingested $1500 \mathrm{mg} / \mathrm{d}$ calcium and $1100 \mathrm{IU} / \mathrm{d}$ vitamin $\mathrm{D}$ (3) for 4-years reduced risk for developing cancer by $>60 \%$.

Low 25-hydroxyvitamin D levels have also been associated with the cardiovascular disease risk factors of hypertension, obesity, and the metabolic syndrome, as well as cardiovascular disease events including stroke and congestive heart failure [70]. Studies suggest vitamin D deficiency may be a contributor to the development of cardiovascular disease potentially through associations with diabetes or hypertension [70]. However, much of the evidence base for this comes from epidemiologic studies of adults. These have been expertly reviewed by Holick [71] and Zittermann [62]. Far less is known of the effect of poor vitamin D status during childhood and adolescence on risk of these nonskeletal chronic diseases. However, in his recent review of childhood vitamin D deficiency, Holick highlights evidence that living at latitudes above $35^{\circ}$ for the first 10 -years of life increases risk of multiple sclerosis by $100 \%$, as well as increasing the risk of several other autoimmune diseases [72]. There is also some evidence that supplementation with vitamin D (usually high dose (20-2500 $\mathrm{mg} /$ day) and in some cases in combination with calcium; (low dose vitamin D supplementation did not appear to be effective) may beneficially influence muscle function, rheumatoid arthritis, blood pressure, blood glucose and insulin levels [62].

After nearly 20-years of debate, there is now sufficient, reproducible evidence supporting a beneficial role for calcium and vitamin D-rich dairy foods in blood pressure regulation [73]. The incidence of hypertension also followed an inverse relation with serum $25(\mathrm{OH}) \mathrm{D}[74,75]$ and increased intake of vitamin $\mathrm{D}$ was associated with 9.3 percent decrease in systolic blood pressure in adults [76], while a more recent study by Saintonge et al. [77] revealed that overweight and obesity in adolescence increases the risk for vitamin $\mathrm{D}$ deficiency compared with the normal ones. Recently, a new study by Kremer et al. [78] confirmed that, by examined the relationship of $25(\mathrm{OH}) \mathrm{D}$ status and body fat levels in 90 post pubertal females and concluded that vitamin $\mathrm{D}$ insufficiency was associated with increased BF.

\section{Treatment}

Rickets can be treated effectively with vitamin D supplementation. In relation to addressing subclinical vitamin $\mathrm{D}$ deficiency and insufficiency, sun exposure and dietary vitamin $\mathrm{D}$ intake (including vitamin $\mathrm{D}$ fortified foods and 
supplemental vitamin D use) undoubtedly have important roles. However, the relative importance of these two routes of exposure differs from summer to winter for most people. If sun exposure is sufficient, very little if any vitamin $D$ is required from the diet during summer [79]. It is worth remembering, however, that the production of vitamin $\mathrm{D}$ in the skin during summer varies with the geographical location, atmospheric conditions, time spent outdoors, clothing, and skin pigmentation [79] as well as sunscreen use. According to Holick, [80] approximately 30 minutes of skin exposure (without sunscreen) of the arms and face to sunlight can provide all the daily vitamin D needs of the body. When sunlight exposure is limited, dietary intakes of vitamin $\mathrm{D}$, if sufficient, can make a significant contribution to vitamin D status. In particular, at latitudes above $37^{\circ} \mathrm{N}$, production of vitamin D3 in winter is virtually zero, because the zenith angle of the sunlight increases in the autumn and winter and consequently, the amount of solar ultraviolet radiation that reaches the Earth's surface is substantially reduced. Therefore, there is an increased reliance on dietary vitamin $\mathrm{D}$ for maintaining adequate vitamin $\mathrm{D}$ status during winter, and even in summer for those who avidly avoid sunshine exposure. While the US authorities recommend $5 \mathrm{mg}$ vitamin D/day for children and adolescents (aged 1-18 years), [5] respectively, in the UK children aged $1-3$ years are recommended $7 \mathrm{mg}$ vitamin $\mathrm{D} /$ day while there is no dietary recommendation for vitamin D for subjects aged 4-64-years [72]. This lack of dietary recommendation is on the basis that it is assumed that skin synthesis of vitamin D will generally ensure adequacy which depends on regular exposure to summer sunlight [72]. If individuals have restricted sunlight exposure, then $10 \mathrm{mg} /$ day is recommended. However, vitamin D is rather sparsely represented in the diet, which might explain the low intakes in children and adolescents during winter, as mentioned earlier. Oily fish such as salmon, mackerel and sardines contain high amounts of vitamin D. Cod liver oil is also an excellent source of vitamin D. Some meats may contain 25(OH)D3. Fortified foods can also be a major contributor to dietary vitamin D2 Vitamin D-fortified foods include some types of margarines, breakfast cereals, infant formulae, fruit juices, chocolates and milks, to name but a few. Use of vitamin D-containing supplements can also make a major contribution to mean daily intake of vitamin $\mathrm{D}$ in both adults and children.

While rickets can be prevented with far smaller doses, a level needed to prevent diabetes would require intake, by children aged $\geq 1$ year, of approximately $25-50 \mu \mathrm{g}$ (1000$2000 \mathrm{IU}$ )/day of vitamin D3, an intake associated with major reduction in incidence in Norway. Such intake has no known adverse health effects in adults. Children aged $\geq 1$ year and who are outdoors in sunlight for a few minutes each day may achieve similar serum levels with smaller oral intake. Pending further research, oral vitamin D intake of infants $<1$ year old should not exceed $6.25 \mu \mathrm{g}$ (250 IU)/day. Physicians and nutritionists should advise parents that children $\geq 1$ year who live more than approximately $30^{\circ}$ from the equator should consume $25-50 \mu \mathrm{g}(1,000-2,000 \mathrm{IU}) /$ day of vitamin D3, especially during winter, to substantially reduce their risk of childhood type 1 diabetes. It is also very important to point out that supplementation with Vit D3 it is more efficient than Vit D2 for increasing 25(OH)D levels. In a study by Trang et al. [81], 72 subjects took $260 \mathrm{nmol}$ (approximately $4000 \mathrm{IU})$ vitamin D2 $(n=17)$ or vitamin D3 $(n=55)$ daily for $14 \mathrm{~d}$. The increase in $25(\mathrm{OH}) \mathrm{D}$ with vitamin D3 was $23.3 \pm 15.7 \mathrm{nmol} / \mathrm{L}$, or 1.7 times the increase obtained with vitamin D2 $(13.7 \pm 11.4 \mathrm{nmol} / \mathrm{L} ; P=.03)$. More recently, Leventis and Kiely [82], reported that vitamin D3 had greater potency than equimolar vitamin D2, with a higher, sustained serum $25(\mathrm{OH}) \mathrm{D}$ response and efficacious PTH suppression.

\section{Conclusions}

There is enough evidence that severe deficiency of vitamin D may lead to skeletal and nonskeletal disease. Both children and adolescents seem to be in high risk of low vitamin D status especially during winter. Having a diet higher in calcium and vitamin $\mathrm{D}$ as well as oral supplementation with vitamin $\mathrm{D}$ may be necessary for children and adolescents not only in the absence of sun exposure in winter time but also in preventing other diseases such as diabetes type 1 , cancer and cardiovascular disease. Further research is needed in order to identify the optimal dietary recommendation needed begging from pregnancy in order to prevent vitamin $\mathrm{D}$ deficiency.

\section{References}

[1] T. D. Thacher, P. R. Fischer, J. M. Pettifor, and G. L. Darmstadt, "Nutritional rickets in ichthyosis and response to calcipotriene," Pediatrics, vol. 114, no. 1, pp. 119-123, 2004.

[2] L. A. G. Armas, B. W. Hollis, and R. P. Heaney, "Vitamin D2 is much less effective than vitamin D3 in humans," Journal of Clinical Endocrinology and Metabolism, vol. 89, no. 11, pp. 5387-5391, 2004.

[3] H. M. Trang, D. E. C. Cole, L. A. Rubin, A. Pierratos, S. Siu, and R. Vieth, "Evidence that vitamin D3 increases serum 25hydroxyvitamin D more efficiently than does vitamin D2," American Journal of Clinical Nutrition, vol. 68, no. 4, pp. 854858, 1998.

[4] L. A. Houghton and R. Vieth, "The case against ergocalciferol (vitamin D2) as a vitamin supplement," American Journal of Clinical Nutrition, vol. 84, no. 4, pp. 694-697, 2006.

[5] Institute of Medicine, Dietary Reference Intakes. For Calcium, Phosphorous, Magnesium, Vitamin D and Fluoride, National Academy Press, Washington, DC, USA, 1997.

[6] S. Fitzpatrick, N. F. Sheard, N. G. Clark, and M. L. Ritter, "Vitamin D-deficient rickets: a multifactorial disease," Nutrition Reviews, vol. 58, no. 7, pp. 218-222, 2000.

[7] M. F. Holick, "Vitamin D: photobiology, metabolism, mechanism of action, and clinical applications," in Premer on the Metabolic Bone Diseases and Disorders of Mineral Metabolism, M. Favus, Ed., pp. 129-137, American Society for Bone and Mineral Research, Washington, DC, USA, 5th edition, 2003.

[8] J. G. Haddad and T. J. Hahn, "Natural and synthetic sources of circulating 25 hydroxyvitamin D in man," Nature, vol. 244, no. 5417, pp. 515-517, 1973. 
[9] Standing Committee on the Scientific Evaluation of Dietary Reference Intakes. Dietary Reference Intakes, Calcium, Phosphorus, Magnesium, Vitamin D, and Fluoride, National Academy Press, Washington, DC, USA, 1997.

[10] P. Weisberg, K. S. Scanlon, R. Li, and M. E. Cogswell, "Nutritional rickets among children in the United States: review of cases reported between 1986 and 2003," The American Journal of Clinical Nutrition, vol. 80, supplement 6, pp. 1697S-705S, 2004.

[11] C. M. Gordon, H. Feldman, L. Sinclair, A. Williams, and J. Cox, "Prevalence of vitamin D deficiency among healthy infants and toddlers," Archives of Pediatrics \& Adolescent Medicine, no. 162, pp. 505-512, 2008.

[12] B. D. Gessner, J. Plotnik, and P. T. Muth, "25-hydroxyvitamin D levels among healthy children in Alaska," Journal of Pediatrics, vol. 143, no. 4, pp. 434-437, 2003.

[13] E. E. Ziegler, B. W. Hollis, S. E. Nelson, and J. M. Jeter, "Vitamin D deficiency in breastfed infants in Iowa," Pediatrics, vol. 118, no. 2, pp. 603-610, 2006.

[14] J. M. Lee, J. R. Smith, B.L. Philipp, T. C. Chen, J. Mathieu, and M. F. Holick, "Vitamin D deficiency in a healthy group of mothers and newborn infants," Clinical Pediatrics, vol. 46, no. 1, pp. 42-44, 2007.

[15] S. S. Sullivan, C. J. Rosen, W. A. Halteman, T. C. Chen, and M. F. Holick, "Adolescent girls in maine are at risk for vitamin D insufficiency," Journal of the American Dietetic Association, vol. 105, no. 6, pp. 971-974, 2005.

[16] K. Rajakumar, J. D. Fernstrom, J. E. Janosky, and S. L. Greenspan, "Vitamin D insufficiency in preadolescent African-American children," Clinical Pediatrics, vol. 44, no. 8, pp. 683-692, 2005.

[17] C. M. Gordon, K. C. DePeter, H. A. Feldman, E. Grace, and S. J. Emans, "Prevalence of vitamin D deficiency among healthy adolescents," Archives of Pediatrics and Adolescent Medicine, vol. 158, no. 6, pp. 531-537, 2004.

[18] A. C. Looker, B. Dawson-Hughes, M. S Calvo, E. W Gunter, and N. R. Sahyoun, "Serum 25-hydroxyvitamin D status of adolescents and adults in two seasonal subpopulations from NHANES III," Bone, vol. 30, no. 5, pp. 771-777, 2002.

[19] M. Lawson and M. Thomas, "Vitamin D concentrations in Asian children aged 2 years living in England: population survey," British Medical Journal, vol. 318, no. 7175, p. 28, 1999.

[20] J. Guillemant, H.-T. Le, A. Maria, A. Allemandou, G. Peres, and S. Guillemant, "Wintertime vitamin D deficiency in male adolescents: effect on parathyroid function and response to vitamin D3 supplements," Osteoporosis International, vol. 12, no. 10, pp. 875-879, 2001.

[21] P. Nicolaidou, Z. Hatzistamatiou, A. Papadopoulou, et al., "Low vitamin D status in mother-newborn pairs in Greece," Calcified Tissue International, vol. 78, no. 6, pp. 337-342, 2006.

[22] G. El-Hajj Fuleihan, M. Nabulsi, M. Choucair, et al., "Hypovitaminosis D in healthy schoolchildren," Pediatrics, vol. 107, no. 4, p. E53, 2001.

[23] I. Pehlivan, S. Hatun, M. Aydogan, K. Babaoglu, and S. A. Gokalp, "Maternal vitamin D defiency and vitamin D supplementation in healthy infants," Turkish Journal of Pediatrics, vol. 45, no. 4, pp. 315-320, 2003.

[24] X. Du, H. Greenfield, D. R. Fraser, K. Ge, A. Trube, and Y. Wang, "Vitamin D deficiency and associated factors in adolescent girls in Beijing," American Journal of Clinical Nutrition, vol. 74, no. 4, pp. 494-500, 2001.
[25] M. Lehtonen-Veromaa, T. Möttönen, K. Irjala, et al., "Vitamin $\mathrm{D}$ intake is low and hypovitaminosis D common in healthy 9- to 15-year-old Finnish girls," European Journal of Clinical Nutrition, vol. 53, no. 9, pp. 746-751, 1999.

[26] T. A. Outila, M. U. M. Karkkainen, and C. J. E. LambergAllardt, "Vitamin D status affects serum parathyroid hormone concentrations during winter in female adolescents: associations with forearm bone mineral density," American Journal of Clinical Nutrition, vol. 74, no. 2, pp. 206-210, 2001.

[27] L. M. Ward, I. Gaboury, M. Ladhani, and S. Zlotkin, "Vitamin D-deficiency rickets among children in Canada," Canadian Medical Association Journal, vol. 177, no. 2, pp. 161-166, 2007.

[28] L. A. Newhook, S. Sloka, M. Grant, E. Randell, C. S. Kovacs, and L. K. Twells, "Vitamin D insufficiency common in newborns, children and pregnant women living in Newfoundland and Labrador, Canada," Maternal and Child Nutrition, vol. 5, no. 2, pp. 186-191, 2009.

[29] A. Bener, M. Al-Ali, and G. F. Hoffmann, "High prevalence of vitamin D deficiency in young children in a highly sunny humid country: a global health problem," Minerva Pediatrica, vol. 61, no. 1, pp. 15-22, 2009.

[30] M. L. Ho, H.-C. Yen, and R. C. Tsang, "Randomized study of sunshine exposure and serum 25-OHD in breast-fed infants in Beijing, China," Journal of Pediatrics, vol. 107, no. 6, pp. 928931, 1985.

[31] F. A. Tylavsky, K. A. Ryder, A. Lyytikainen, and S. Cheng, "Vitamin D, parathyroid hormone, and bone mass in adolescents," Journal of Nutrition, vol. 135, no. 11, pp. 2735S-2738S, 2005.

[32] B. Dawson-Hughes, G. E. Dallal, E. A. Krall, S. Harris, L. J. Sokoll, and G. Falconer, "Effect of vitamin D supplementation on wintertime and overall bone loss in healthy postmenopausal women," Annals of Internal Medicine, vol. 115, no. 7, pp. 505-512, 1991.

[33] J. Gregory, S. Lowe, C. J. Bates, et al., "National Diet and Nutrition Survey: young people aged 4 to 18 years," The Stationery Office, London, UK, 2000.

[34] J. E. Rockell, T. J. Green, C. M. Skeaff, et al., "Season and ethnicity are determinants of serum 25-hydroxyvitamin D concentrations in New Zealand children aged 5-14 years," Journal of Nutrition, vol. 135, no. 11, pp. 2602-2608, 2005.

[35] C. Moore, M. M. Murphy, D. R. Keast, and M. F. Holick, "Vitamin D intake in the United States," Journal of the American Dietetic Association, vol. 104, no. 6, pp. 980-983, 2004.

[36] A. C. Looker, C. M. Pfeiffer, D. A. Lacher, R. L. Schleicher, M. F. Picciano, and E. A. Yetley, "Serum 25-hydroxyvitamin D status of the US population: 1988-1994 compared with 2000-2004," American Journal of Clinical Nutrition, vol. 88, no. 6, pp. 15191527, 2008.

[37] F. N. Ali, L. M. Arguelles, C. B. Langman, and H. E. Price, "Vitamin D deficiency in children with chronic kidney disease: uncovering an epidemic," Pediatrics, vol. 123, no. 3, pp. 791796, 2009.

[38] J. McGrath, “Does 'imprinting' with low prenatal vitamin D contribute to the risk of various adult disorders?" Medical Hypotheses, vol. 56, no. 3, pp. 367-371, 2001.

[39] T. D. Thacher, P. R. Fischer, M. A. Strand, and J. M. Pettifor, "Nutritional rickets around the world: causes and future directions," Annals of Tropical Paediatrics, vol. 26, no. 1, pp. $1-16,2006$. 
[40] R. W. Chesney, "Rickets: the third wave," Clinical Pediatrics, vol. 41, no. 3, pp. 137-139, 2002.

[41] N. R. Belton, "Rickets-not only the "English disease"'" Acta Paediatrica Scandinavica, vol. 75, no. 323, pp. S68-S75, 1986.

[42] B. R. Pal and N. J. Shaw, "Rickets resurgence in the United Kingdom: improving antenatal management in Asians," Journal of Pediatrics, vol. 139, no. 2, pp. 337-338, 2001.

[43] S. Ashraf and M. Z. Mughal, "The prevalence of rickets among non-Caucasian children," Archives of Disease in Childhood, vol. 87, no. 3, pp. 263-264, 2002.

[44] A. M. Bonet, S. N. Lopez, A. R. Besora, P. S. Herrero, T. E. Esteban, and P. V. Seidel, "Rickets in Asian immigrants during puberty," Anales Espanoles de Pediatria, vol. 57, no. 3, pp. 264267, 2002.

[45] S. N. Lopez, A. M. Bonet, and A. O. Garcia, "Rickets in Asian immigrants," Anales Espanoles de Pediatria, vol. 57, no. 3, pp. 227-230, 2002.

[46] P. C. Dagnelie, F. J. V. R. A. Vergote, W. A. Van Staveren, H. van den Berg, P. G. Dingjan, and J. G. A. J. Hautvast, "High prevalence of rickets in infants on macrobiotic diets," American Journal of Clinical Nutrition, vol. 51, no. 2, pp. 202208, 1990.

[47] K. W. Feldman, E. K. Marcuse, and D. A. Springer, "Nutritional rickets," American Family Physician, vol. 42, no. 5, pp. 1311-1318, 1990.

[48] M. S. Al-Atawi, I. A. Al-Alwan, A. N. Al-Mutair, H. M. Tamim, and N. A. Al-Jurayyan, "Epidemiology of nutritional rickets in children," Saudi Journal of Kidney Diseases and Transplantation, vol. 20, no. 2, pp. 260-265, 2009.

[49] R. A. Etzel, S. J. Balk, C. F. Bearer, et al., "Ultraviolet light: a hazard to children. Committee on Environmental Health," Pediatrics, vol. 104, no. 2, pp. 328-333, 1999.

[50] L. M. Oginni, M. Worsfold, O. A. Oyelami, C. A. Sharp, D. E. Powell, and M. W. J. Davie, "Etiology of rickets in Nigerian children," Journal of Pediatrics, vol. 128, no. 5, pp. 692-694, 1996.

[51] T. D. Thacher, S. I. Ighogboja, and P. R. Fischer, "Rickets without vitamin D deficiency in Nigerian children," Ambulatory Child Health, vol. 3, no. 1, pp. 56-64, 1997.

[52] H. E. Maltz, M. B. Fish, and M. A. Holliday, "Calcium deficiency rickets and the renal response to calcium infusion," Pediatrics, vol. 46, no. 6, pp. 865-870, 1970.

[53] S. W. Kooh, D. Fraser, B. J. Reilly, J. R. Hamilton, D. G. Gall, and L. Bell, "Rickets due to calcium deficiency," The New England Journal of Medicine, vol. 297, no. 23, pp. 1264-1266, 1977.

[54] N. F. Carvalho, R. D. Kenney, P. H. Carrington, and D. E. Hall, "Severe nutritional deficiencies in toddlers resulting from health food milk alternatives," Pediatrics, vol. 107, no. 4, p. E46, 2001.

[55] P. Wilton, "Cod-liver oil, vitamin D and the fight against rickets," Canadian Medical Association Journal, vol. 152, no. 9, pp. 1516-1517, 1995.

[56] N. J. Shaw and B. R. Pal, "Vitamin D deficiency in UK Asian families: activating a new concern," Archives of Disease in Childhood, vol. 86, no. 3, pp. 147-149, 2002.

[57] K. S. Agarwal, M. Z. Mughal, P. Upadhyay, J. L. Berry, E. B. Mawer, and J. M. Puliyel, "The impact of atmospheric pollution on vitamin D status of infants and toddlers in Delhi, India," Archives of Disease in Childhood, vol. 87, no. 2, pp. 111113, 2002.

[58] S. Sloka, M. Grant, and L. A. Newhook, "Time series analysis of ultraviolet $\mathrm{B}$ radiation and type 1 diabetes in
Newfoundland," Pediatric Diabetes, vol. 9, no. 2, pp. 81-86, 2008.

[59] S. S. Harris, "Vitamin D in type 1 diabetes prevention," Journal of Nutrition, vol. 135, no. 2, pp. 323-325, 2005.

[60] C. S. Zipitis and A. K. Akobeng, "Vitamin D supplementation in early childhood and risk of type 1 diabetes: a systematic review and meta-analysis," Archives of Disease in Childhood, vol. 93, no. 6, pp. 512-517, 2008.

[61] K. Badenhoop, "Solar power to prevent type 1 diabetes?" Pediatric Diabetes, vol. 9, no. 2, pp. 79-80, 2008.

[62] A. Zittermann, "Vitamin D in preventive medicine: are we ignoring the evidence?" British Journal of Nutrition, vol. 89, no. 5, pp. 552-572, 2003.

[63] S. B. Mohr, C. F. Garland, E. D. Gorham, and F. C. Garland, "The association between ultraviolet B irradiance, vitamin D status and incidence rates of type 1 diabetes in 51 regions worldwide," Diabetologia, vol. 51, no. 8, pp. 1391-1398, 2008.

[64] E. Hyppönen, E. Läärä, A. Reunanen, M.-R. Järvelin, and S. M. Virtanen, "Intake of vitamin D and risk of type 1 diabetes: a birth-cohort study," The Lancet, vol. 358, no. 9292, pp. 15001503, 2001.

[65] L. C. Stene and G. Joner, "Use of cod liver oil during the first year of life is associated with lower risk of childhood-onset type 1 diabetes: a large, population-based, case-control study," American Journal of Clinical Nutrition, vol. 78, no. 6, pp. 11281134, 2003.

[66] B. M. Svoren, L. K. Volkening, J. R. Wood, and L. M. B. Laffel, "Significant vitamin D deficiency in youth with type 1 diabetes mellitus," Journal of Pediatrics, vol. 154, no. 1, pp. 132-134, 2009.

[67] C. M. Fronczak, A. E. Barón, H. P. Chase, et al., "In utero dietary exposures and risk of islet autoimmunity in children," Diabetes Care, vol. 26, no. 12, pp. 3237-3242, 2003.

[68] H. K. Brekke and J. Ludvigsson, "Vitamin D supplementation and diabetes-related autoimmunity in the ABIS study," Pediatric Diabetes, vol. 8, no. 1, pp. 11-14, 2007.

[69] M. F. Holick, "Vitamin D and sunlight: strategies for cancer prevention and other health benefits," Clinical Journal of the American Society of Nephrology, vol. 3, no. 5, pp. 1548-1554, 2008.

[70] E. D. Michos and M. L. Melamed, "Vitamin D and cardiovascular disease risk," Current Opinion in Clinical Nutrition and Metabolic Care, vol. 11, no. 1, pp. 7-12, 2008.

[71] M. F. Holick, "Sunlight and vitamin D for bone health and prevention of autoimmune diseases, cancers, and cardiovascular disease," The American Journal of Clinical Nutrition, vol. 80, supplement 6, pp. 1678S-88S, 2004.

[72] M. F. Holick, "Resurrection of vitamin D deficiency and rickets," Journal of Clinical Investigation, vol. 116, no. 8, pp. 2062-2072, 2006.

[73] T. A. Nicklas, "Calcium intake trends and health consequences from childhood through adulthood," Journal of the American College of Nutrition, vol. 22, no. 5, pp. 340-356, 2003.

[74] S. G. Rostand, "Ultraviolet light may contribute to geographic and racial blood pressure differences," Hypertension, vol. 30, no. 2, pp. 150-156, 1997.

[75] R. Krause, M. Buhring, W. Hopfenmuller, M. F. Holick, and A. M. Sharma, "Ultraviolet B and blood pressure," The Lancet, vol. 352, no. 9129, pp. 709-710, 1998.

[76] M. Pfeifer, B. Begerow, H. W. Minne, D. Nachtigall, and C. Hansen, "Effects of a short-term vitamin D3 and calcium supplementation on blood pressure and parathyroid hormone levels in elderly women," Journal of Clinical Endocrinology and Metabolism, vol. 86, no. 4, pp. 1633-1637, 2001. 
[77] S. Saintonge, H. Bang, and L. M. Gerber, "Implications of a new definition of vitamin $\mathrm{D}$ deficiency in a multiracial US adolescent population: the national health and nutrition examination survey III," Pediatrics, vol. 123, no. 3, pp. 797803, 2009.

[78] R. Kremer, P. P. Campbell, T. Reinhardt, and V. Gilsanz, "Vitamin D status and its relationship to body fat, final height, and peak bone mass in young women," Journal of Clinical Endocrinology and Metabolism, vol. 94, no. 1, pp. 67-73, 2009.

[79] Department of Health, "Nutrition and bone health: with particular reference to calcium and vitamin D," Report on health and social subjects, The Stationary Office, London, UK, 1998.

[80] M. F. Holick, "McCollum award lecture, 1994: vitamin Dnew horizons for the 21st century," American Journal of Clinical Nutrition, vol. 60, no. 4, pp. 619-630, 1994.

[81] H. M. Trang, D. E. C. Cole, L. A. Rubin, A. Pierratos, S. Siu, and R. Vieth, "Evidence that vitamin D3 increases serum 25hydroxyvitamin D more efficiently than does vitamin D2," American Journal of Clinical Nutrition, vol. 68, no. 4, pp. 854858, 1998.

[82] P. Leventis and P. D. W. Kiely, "The tolerability and biochemical effects of high-dose bolus vitamin D2 and D3 supplementation in patients with vitamin D insufficiency," Scandinavian Journal of Rheumatology, vol. 38, no. 2, pp. 149153, 2009. 


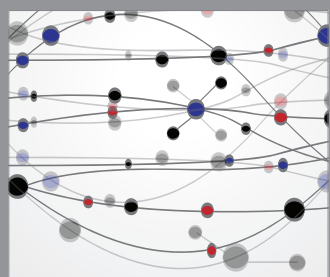

The Scientific World Journal
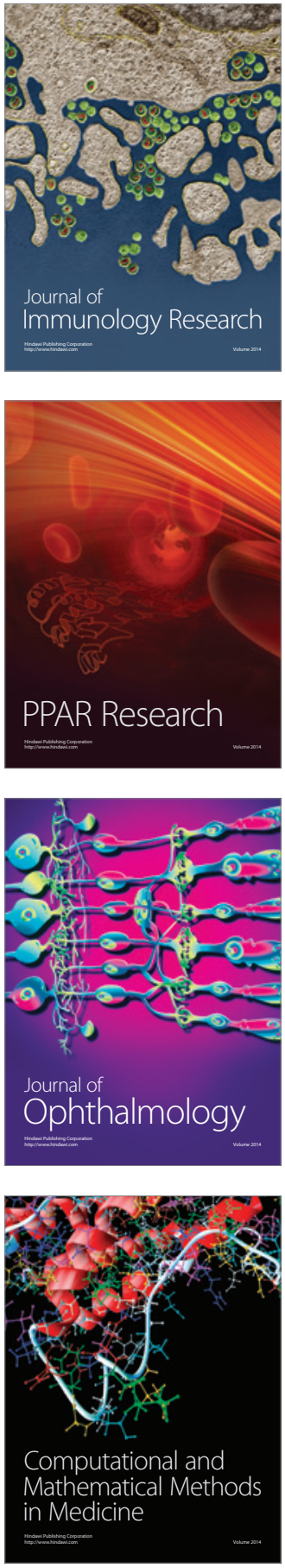

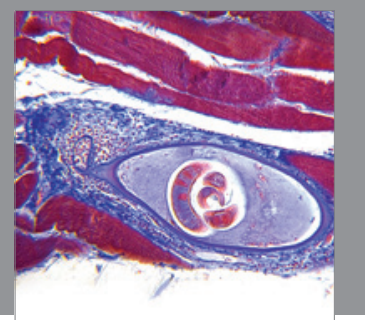

Gastroenterology

Research and Practice
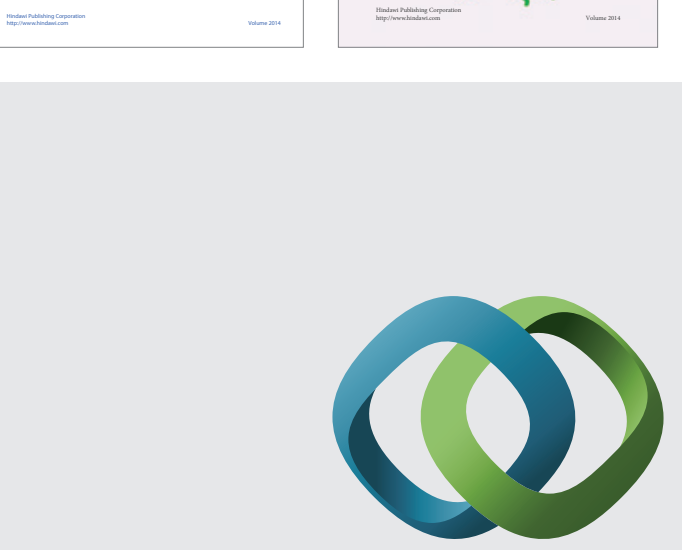

\section{Hindawi}

Submit your manuscripts at

http://www.hindawi.com
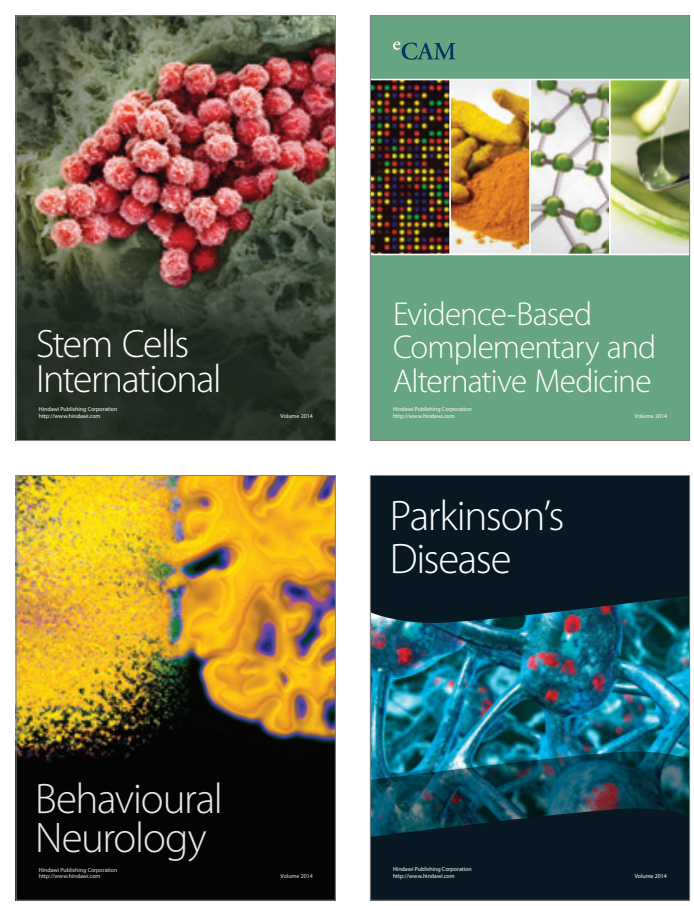

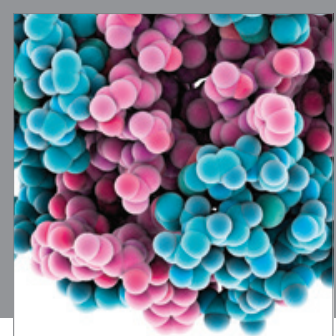

Journal of
Diabetes Research

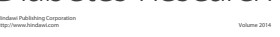

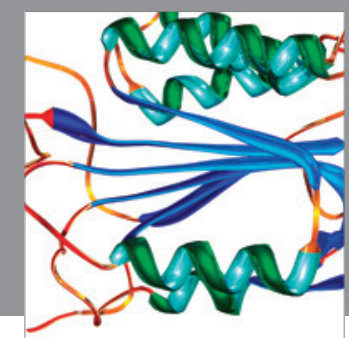

Disease Markers
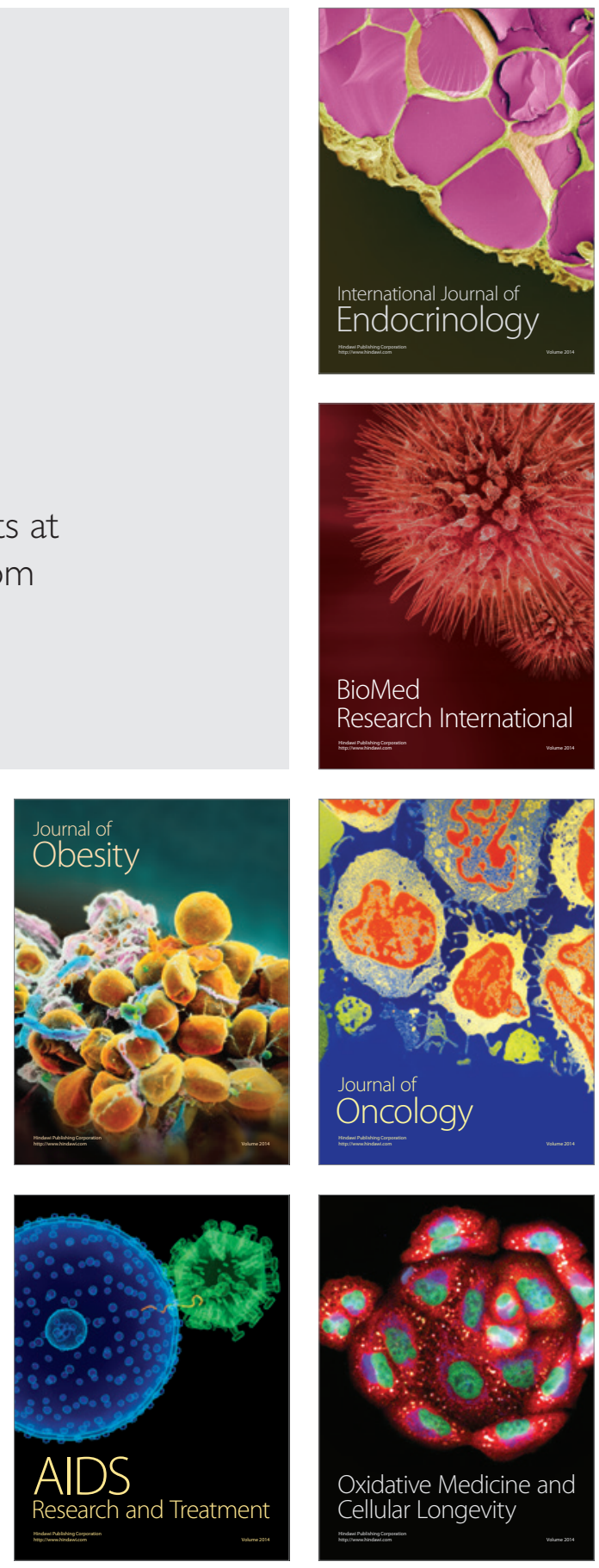